\title{
Differences Between NRS-2002 and MUST in Relation to the Metabolic Condition of Trauma Patients
}

\section{Oktaffrastya Widhamurti Septafani ${ }^{1}$, Suharto Suharto $^{2}$ and Harmayetty Harmayetty ${ }^{1}$}

1 Faculty of Nursing, Universitas Airlangga, Surabaya, Indonesia

2 Faculty of Medicine, Universitas Airlangga, Surabaya, Indonesia

\begin{abstract}
Introduction: Flow phase with high cardiac output and increased metabolic conditions. When metabolic conditions are not stable there will be a long duration of complications until death. One of the benefits of Nutrition Risk Screening (NRS2002) is reliable inpatient care for critical patients. While the Malnutrition Universal Screening Tool (MUST) shows speed in the classification of nutritional disorders.
\end{abstract}

Methods: This study used the observational design method. The sampling technique in this study used Consecutive sampling in accordance with the criteria consisting of 31 respondents. This was to determine the specificity and sensitivity values of NRS 2002 and MUST using contingency table analysis and for the Area Under Curve (AUC) using Receiver Operating Characteristic (ROC) curve analysis.

Results: The sensitivity values in MUST was predicted for metabolic conditions which was higher than when using NRS 2002, but the specificity and value of AUC (Area Under Curve) was higher using NRS 2002 than using MUST when it came to predicting metabolic conditions.

Conclusions: There were differences in effectiveness between use of Nutritional Risk Screening (NRS-2002) with the Malnutrition Universal Screening Tool (MUST) in relation to changes in metabolic conditions of trauma patients. NRS2002 is more effective than MUST. NRS 2002 has the ability to identify patients more precisely who are likely to have a negative outcome.

\section{ARTICLE HISTORY}

Received: February 01, 2018

Accepted: June 07, 2018

\section{KEYWORDS}

NRS 2002; MUST; metabolic response; trauma

\section{CONTACT}

Oktaffrastya Widhamurti Septafani

\oktaffrastyaws@gmail.com

$\ggg$ Faculty of Nursing,

Universitas Airlangga,

Surabaya, Indonesia

Cite this as: Septafani, O., Suharto, S., \& Harmayetty, H. (2018). Differences Between NRS-2002 and MUST in Relation to the Metabolic Condition of Trauma Patients. Jurnal Ners, 13(1), 80-86. doi:http://dx.doi.org/10.20473/in.v13i1.7518

\section{INTRODUCTION}

Trauma is the most common cause of death in the productive age group of 16-44 years old worldwide (MacLeod, 2005). The metabolic response to human trauma has been defined as having 3 stages: ebb phase or decreased metabolic rate in the early shock phase, flow phase or catabolic phase, and the anabolic phase. The ebb phase begins immediately after the injury or trauma and lasts for 0-48 hours. The ebb phase is characterised by tissue hypoperfusion and decreased overall metabolic activity. The flow phase, which includes a catabolic phase characterized by high cardiac output and increased metabolic conditions. Typically, the peak flow phase is about 3-5 days, and this will drop in 7-10 days. Late death is when the patient dies several days or weeks after the trauma. The prevalence of trauma deaths occurring in this period is $10 \%-20 \%$
(Sobrino \& Shafi, 2013). Increased metabolic conditions include the hyper-dynamic characteristics of heart rate, increased energy expenditures, increased solubility of glycogen and protein, and a loss of muscle mass and weight, leading to delayed wound healing and immune system depression (Lee, Benjamin \& Herndon, 2005). If the metabolic condition is not handled properly then it will lead to a longer period of treatment, complications and death. So far predicting metabolic condition is based on laboratory results by looking at the magnitude of plasma proteins, nitrogen balance and the result of immunological function tests. However, there are often errors in the pre-analytic stages of laboratory examination when it comes to initial preparation compared to errors in the analytical phase (Plebani, 2012). As a result there are still some specimens received by the laboratory experiencing hemolysis, so it cannot be checked according to clinical request. 
In a study conducted by Chen et al., the sensitivity (94.5\%) of Nutritional Risk Screening (NRS-2002) was high when it came to identifying nutritional disorders compared to Routine Clinical Laboratory Measurements (RCLMs) (Chen et al., 2015). For nutrition risk screening in adult patients, the European Society for Clinical Nutrition and Metabolism currently recommend Nutritional Risk Screening (NRS-2002) as the screening tool of choice (Kuppinger et al., 2013). NRS-2002 showed superior performance (higher sensitivity and specificity for predicting complications) compared to other screening tools such as the Malnutrition Universal Screening Tool (MUST). The study comparing MUST with NRS 2002 showed that MUST is significantly associated with complications in postoperative patients. with a sensitivity value of $23.1 \%$ and a specificity of $86.8 \%$ (Lomivorotov et al., 2013).

The results of nutritional screening can determine the patient's status and detect some of the complications of critical illness (Al Kalaldeh \& Shahin, 2014). Based on the recommendation of the British Association of Parenteral and Enteral Nutrition (BAPEN), simple and easy nutrition observation devices can be used to demonstrate the risks of nutritional problems in patients requiring comprehensive advanced examination. Every nutritional screening device should have the property of being easy and fast to use and interpret, be valid and have a good level of acceptance so each patient can subsequently receive a nutrition care pattern that is appropriate to their condition (Weekes, Elia, \& Emery, 2004). Currently, many nutrition observation devices in hospitals have been developed for various purposes, such as to adjust the measured population, or to find new methods that are faster and easier to use. One of the recommendations of the European Society for Parenteral and Enteral Nutrition (ESPEN) is Nutrition Risk Screening (NRS-2002) which assesses patients based on two components, malnutrition and the severity of disease with no category, mild, moderate, and severe being in the result categories respectively. The NRS-2002 device is also known to be valid and easy to use in European trial populations (Kondrup, et al., 2003). In some studies, it showed Nutrition Risk Screening (NRS-2002) has a high specificity and sensitivity value compared to other nutritional screening values.

BAPEN developed the Malnutrition Universal Screening Tools (MUST) that performs an examination with 3 main criteria: current weight, a large amount of unwanted weight loss, and the presence of acute illness. The score each criterion is between 0,1 , or 2 . Based on the MUST assessment, patients are classified as low, moderate, and high risk (Malnutrition Advisory Group, 2003). In Jayawardena et al.'s study (2016), there is a Malnutrition Universal Screening Tools (MUST) relationship to the patient's clinical situation. The study demonstrated the high specificity of Malnutrition Universal Screening Tools (MUST) in predicting outcome value of patients with heart failure.

The purpose of this study was to explain the difference in effectiveness between the uses of Nutritional Risk Screening Instruments (NRS-2002) with the Malnutrition Universal Screening Tool (MUST) in relation to changes in metabolic conditions in trauma patients.

\section{MATERIALS AND METHODS}

The Committee of Ethical Approval in the Faculty of Nursing Universitas Airlangga has carefully reviewed the research proposal presented and approved this research study by way the full board method. This study used an observational design. Observational studies are an alternative to experimental studies. An observational study is sometimes termed a natural experiment. The study subjects were classified into groups with the presence or absence of a disease respectively, which is called a casecontrol study. In this design, an observation or posttest measurement was performed. Diagnostic analysis by examination of albumin and hemoglobin were gold standard. The population in this study was made up of all trauma patients who were treated at Petrokimia Gresik Hospital. The patients who became part of sample must have meet the inclusion criterion. The establishment of the inclusion is criteria as follows: (1) Treatment of trauma $>2$ days (in flow phase). (2) Patients who are trauma by serious trauma. Severe trauma based on AIS (Abbreviated Injury Scale). The while the exclusion criteria that the researchers set include (1) Patients with hyperthyroid disease; (2) Patients with heart failure; (3) Hypertensive patients on beta-blocker therapy; (4) The patient is pregnant; (5) Patients with diabetes and (6) Patients with impaired renal function. The independent variables were the Nutritional Risk Screening (NRS-2002) and the Malnutrition Universal Screening Tool (MUST). Dependent variable was metabolic condition measured by blood urea and blood sugar. Gold Standard nutritional status was measured by the albumin and hemoglobin blood levels of the trauma patients. Each respondent recorded the results of the blood urea examination, blood sugar and the examination of albumin and hemoglobin was done as standard by seeing the patient's medical record. If there was no data in their medical record, then a blood test was done.

According to Leuenberger (2010), NRS 2002 devices have been accepted and widely used in Europe. The device uses four pre-screening statements to separate patients at lower risk of malnutrition from those with a higher risk. This include forms of disease severity, making this device capable of covering patients in all categories of illness in hospitals. NRS 2002 is a device that is easy to use and fast (its use takes only 2-3 minutes). Based on screening conducted with this method, the patients are classified in the normal category (score 
$=0$ ), mild category (score $=1$ ), moderate category (score $=2$ ), or weight category (score $=3$ ).

There are 5 step to perform when screening using MUST, i.e. [1] the collection of anthropometric data collection such as height, weight, and BMI, [2] the scoring of malnutrition risk based on undesirable weight loss, [3] if there is an acute illness which affects the risk of malnutrition, and then the score plus 2, [4] the summation of the scores based on measurements, where the score $0=$ low risk, score 1 = medium risk, or score $\geq 2$ high risk malnutrition, and [5] is the last step where planning measures are undertaken thet are appropriate to the patient's malnutrition risks.

To determine the specificity and sensitivity of Nutritional Risk Screening (NRS-2002) and the Malnutrition Universal Screening Tool (MUST) in relation to metabolic conditions (the values of urea and blood sugar levels) and standard nutritional status (albumin and hemoglobin values) using contingency table analysis, and for the Area Under Curve (AUC) using Receiver Operating Characteristic (ROC) curve analysis.

\section{RESULTS}

Based on the analysis of Table 1, it was found that the sensitivity value of NRS - 2002 in relation to the risk of malnutrition seen in the results of laboratory test was $62.5 \%$. NRS-2002 has the ability to screen trauma patients who are at risk of malnutrition which was $62.5 \%$. The specificity value of NRS 2002 against the risk of malnutrition as seen from the laboratory results was $100 \%$. NRS-2002 has the ability to detect negative results in trauma patients, so the ability of NRS-2002 to screen trauma patients with absolutely no risk of malnutrition was $100 \%$. Positive predictive value $\mathrm{a} /(\mathrm{a}+\mathrm{b}) \times 100=5 /(5$ $+0) \times 100=100 \%$. This indicates that the true proportion of trauma patients included in the category of malnutrition risk was $100 \%$. The negative predictive value $d /(c+d) \times 100=17 /(3$ $+17) \times 100=85 \%$. This indicates that the proportion of trauma patients who are not actually included in the malnutrition risk category was $85 \%$.

Based on the analysis of Table 2 it was found that the MUST sensitivity value in relation to the risk malnutrition risk seen laboratory result was $75 \%$. MUST has the ability to screen trauma patients who are at risk of malnutrition standing at 75\%. MUST specificity value against malnutrition risk seen from laboratory result was $64.7 \%$. MUST has the ability to detect negative outcomes in trauma patients, so the ability of MUST to screen trauma patients with absolutely no risk of malnutrition was $64.7 \%$. Positive predictive value $\mathrm{a} /(\mathrm{a}+\mathrm{b}) \times 100=6 /(6+$ 6) $\times 100=50 \%$. This suggests that the true proportion of trauma patients included in the category of malnutrition risk was $50 \%$. The negative predictive value $d /(c+d) \times 100=11 /(2+11) \times 100$ $=84 \%$. This indicates that the true proportion of
Table 1 . The results of the test validity (specificity and sensitivity) in relation to the use of Nutritional Risk Screening (NRS-2002) used to calculate the risk of malnutrition as seen from the laboratory test (albumin and hemoglobin)

\begin{tabular}{lcc}
\hline NRS 2002 & $\begin{array}{c}\text { Malnutrition } \\
\text { risk } \\
\text { (Low albumin } \\
\text { and hemoglobin } \\
\text { levels) }\end{array}$ & $\begin{array}{c}\text { Normal } \\
\text { (Normal } \\
\text { albumin and } \\
\text { hemoglobin } \\
\text { levels) }\end{array}$ \\
\cline { 2 - 3 } nalnutrition & 5 & $\mathbf{n}$ \\
\hline risk & 3 & 0 \\
Normal & $\mathrm{n}$ & 17 \\
\hline & $\mathrm{Se}=62,5 \%$ & $\mathrm{Sp}=100 \%$ \\
\hline
\end{tabular}

Table 2 . The results of the test validity (specificity and sensitivity) on the use of the Malnutritional Universal Screening Tool (MUST) used to calculate the risk of malnutrition as seen from the laboratory test (albumin and hemoglobin)

\begin{tabular}{lcc}
\hline MUST & $\begin{array}{c}\text { Malnutrition } \\
\text { risk } \\
\text { (low albumin } \\
\text { and hemoglobin } \\
\text { levels) }\end{array}$ & $\begin{array}{c}\text { Normal } \\
\text { (normal } \\
\text { albumin and } \\
\text { hemoglobin } \\
\text { levels) }\end{array}$ \\
\cline { 2 - 3 } & $\mathbf{n}$ & $\mathbf{N}$ \\
\hline $\begin{array}{l}\text { Malnutrition } \\
\text { risk }\end{array}$ & 6 & 6 \\
Normal & 2 & 11 \\
\hline & $\mathrm{Se}=75 \%$ & $\mathrm{Sp}=4.7 \%$ \\
\hline
\end{tabular}

Table 3. The result of the test validity (specificity and sensitivity) on the use of Nutritional Risk Screening (NRS-2002) in relation to metabolic response as seen from laboratory test (BUN and blood glucose)

\begin{tabular}{lcc}
\hline NRS 2002 & $\begin{array}{c}\text { Metabolic } \\
\text { response } \\
\text { (High BUN and } \\
\text { blood glucose } \\
\text { levels }\end{array}$ & $\begin{array}{c}\text { Normal } \\
\text { (Normal BUN } \\
\text { and blood } \\
\text { glucose levels) }\end{array}$ \\
\cline { 2 - 3 } & $\mathbf{n}$ & $\mathbf{N}$ \\
\hline $\begin{array}{l}\text { Malnutrition } \\
\text { risk }\end{array}$ & 4 & 0 \\
Normal & 11 & 7 \\
\hline & $\mathrm{Se}=26.7 \%$ & $\mathrm{Sp}=100 \%$ \\
\hline
\end{tabular}

Table 4 . The results of the test validity (specificity and sensitivity) on the use of the Malnutritional Universal Screening Tool (MUST) in relation to metabolic response as seen from laboratory test (BUN and blood glucose)

\begin{tabular}{lcc}
\hline NRS 2002 & $\begin{array}{c}\text { Metabolic } \\
\text { response } \\
\text { (High BUN and } \\
\text { blood glucose } \\
\text { levels }\end{array}$ & $\begin{array}{c}\text { Normal } \\
\text { (Normal BUN } \\
\text { and blood } \\
\text { glucose levels) }\end{array}$ \\
\cline { 2 - 3 } Malnutrition & $\mathbf{n}$ & $\mathbf{n}$ \\
risk & 7 & 3 \\
Normal & 8 & 4 \\
\hline
\end{tabular}


trauma patients not included in the malnutrition risk category was at $84 \%$.

Based on the analysis of Table 3 , it was found that the sensitivity value of NRS - 2002 in relation to metabolic response as seen results of laboratory results was $26.7 \%$, which means that NRS-2002 has the ability to screen trauma patients who actually enter a metabolic response condition at $26.7 \%$. The specificity value of NRS - 2002 to metabolic response as seen from laboratory result was $100 \%$. The ability of NRS-2002 to screen trauma patients who are completely excluded from metabolic conditions was $100 \%$. Positive predictive value $\mathrm{a} /(\mathrm{a}+\mathrm{b}) \times 100=4$ $/(4+0) \times 100=100 \%$. This indicates that the true proportion of trauma patients included in the metabolic condition was $100 \%$. The negative predictive value $d /(c+d) \times 100=7 /(11+7) \times 100$ $=38 \%$. This suggests that the proportion of trauma patients actually excluded from entry into metabolic conditions was as much as $38 \%$.

Based on analysis of Table 4 , it was found that MUST's sensitivity value in relation to metabolic response seen in the result of laboratory test was $46.6 \%$. MUST has the ability to screen trauma patients who actually experience entry with metabolic conditions at $46.6 \%$. The specificity of MUST was $57.1 \%$. MUST has the ability to detect negative outcomes in trauma patients. The ability of MUST to screen trauma patients who are completely excluded from metabolic conditions was 57.1\%. Positive predictive value a / $(\mathrm{a}+\mathrm{b}) \times 100=7 /(7+$ 3) $\times 100=70 \%$. This suggests that the true proportion of trauma patients included in the metabolic condition was as much as $70 \%$. The negative predictive value $d /(c+d) \times 100=4 /(8+$ 4) $\times 100=33 \%$. This suggests that the proportion of trauma patients who are completely excluded from metabolic conditions was 33\%.

\section{DISCUSSION}

Comparing specificity, sensitivity and AUC (Area Under Curve) on the use of Nutritional Risk Screening (NRS-2002) in relation to metabolic response in trauma patients and gold standards of nutrition

Based on the analysis of Table 3, it was found that the sensitivity value of NRS - 2002 in relation to metabolic response s seen in laboratory results was $26.7 \%$, which means that NRS-2002 has the ability to screen trauma patients who actually enter at metabolic response condition at 26,7\%. Based on the analysis Table 1, it was found that the sensitivity value of NRS - 2002 used to calculate the risk of malnutrition as seen in the laboratory test was $62.5 \%$. NRS-2002 has the ability to screen trauma patients who are actually at risk of malnutrition: the result was $62.5 \%$. It can be seen that the sensitivity of NRS-2002 in relation to metabolic response was low compared to the gold standard. However, the NRS-2002 sensitivity value against the standard was still low, when compared to the research conducted by Ansari, et al. (2014). In the study conducted by Ansari, et al. (2014), obtaining a sensitivity score against the gold standard was $82.4 \%$. This is in contrast to research conducted by Simanjuntak (2010), which obtained a sensitivity value of $53.7 \%$ against the standard. This suggests that the higher albumin and hemoglobin levels the lower the NRS2002 score, which means that there is less risk of malnutrition.

High sensitivity is required if the disease is highly lethal and early detection can significantly improve prognosis (Richard, et al., 2003). The purpose of screening itself is to prevent disease or disease by identifying individuals at a point when the disease process can be changed through intervention. Since the NRS-2002 sensitivity rating for metabolic conditions is low, it cannot be said that the higher the metabolic response value of BUN and blood glucose, that the NRS-2002 score is also small. This is although the metabolic response is associated with the risk of malnutrition.

Low sensitivity values indicate a high false negative value, which occurred in as many as 11 patients. This was where the patients experience a metabolic response characterised by increased BUN and blood glucose but no risk of malnutrition. The risk of malnutrition is strongly related to the total amount of protein taken in per day (William, et al., 2004). This is because it is directly related to albumin and blood hemoglobin levels. In this study, the majority of patients were elective surgery patients, but here the researchers did not classify which patients were due elective surgery and which were not. In a study conducted by Azizah (2010), it showed that a high intake of daily protein will increase BUN and blood glucose.

The specificity value of NRS - 2002 in relation to metabolic response as seen from the laboratory test was $100 \%$. The ability of NRS-2002 to screen trauma patients who were completely excluded from having a metabolic conditions was $100 \%$. The specificity value of NRS - 2002 used to calculate the risk of malnutrition as seen from the laboratory results was $100 \%$. NRS-2002 has the ability to detect negative results in trauma patients, so the ability of NRS-2002 to screen trauma patients with absolutely no risk of malnutrition was $100 \%$. Here the specificity value of NRS-2002 in relation to metabolic response was very high. This is consistent with Richard, et al.'s study (2003) who state that if you want to get a specificity value of $100 \%$ then the value of sensitivity should be less than $100 \%$. An increase in sensitivity will cause a decrease in specificity, and vice versa. NRS-2002 obtains a perfect specificity value because a falsepositive value is equal to 0 .

The value of AUC between NRS - 2002 in relation to BUN and blood glucose levels was $58 \%$ and $59 \%$ with $95 \%$ confidence interval. The value of AUC between NRS-2002 on relation to albumin and hemoglobin levels was $77.3 \%$ and $64.3 \%$ with $95 \%$ confidence interval. NRS-2002 has a moderate value of accuracy to calculate the risk of malnutrition, but 
NRS 2002 has a weak accuracy to relation to metabolic conditions. The research conducted by Ansari, et al. (2013), it showed that get an AUC's value of $58.3 \%$ to calculate albumin levels.

Comparing specificity, sensitivity and AUC (Area Under Curve) on the use the Malnutrition Universal Screening Tool (MUST) in relation to metabolic conditions in trauma patients and gold standards of a nutrition

Based on the analysis of Table 4 it was found that the sensitivity of MUST in relation to the metabolic response as seen results of the laboratory test was $46.6 \%$. MUST has the ability to screen trauma patients. Based on the analysis conducted on Table 2, it was found that the MUST sensitivity value against malnutrition risk as seen in laboratory test was $75 \%$. MUST has the ability to screen trauma patients who are actually at risk of malnutrition at $75 \%$. This suggests that the MUST sensitivity value of the metabolic response is lower when compared to the MUST sensitivity of the risk of malnutrition.

The specificity of MUST on metabolic response as seen from the laboratory test was $57.1 \%$. MUST has the ability to detect negative outcomes in trauma patients. The ability of MUST to screen trauma patients who are completely excluded from metabolic conditions was 57.1\%. MUST's specificity value on malnutrition risk as seen from the laboratory test was $64.7 \%$. MUST has the ability to detect negative outcomes in trauma patients, so the ability of MUST to screen trauma patients with absolutely no risk of malnutrition was $64.7 \%$. This suggests that MUST's specificity value for metabolic response is lower than that of MUST and the risk of malnutrition. The low specificity of the specificity is not a problem, since most of the trauma patients in this study were post-operative patients, there may be various complications (Lomivorotov et al., 2013). Malnutrition itself still means thet there are less extensive and different understandings of the nutritional risks, which can be interpreted as a change in nutritional status for the better or worse because the results of the disease or post-trauma, depending on the actual or potential nutrients and metabolic status (Sun, et al 2015). The theory between trauma, metabolic response and death is related (Simsek, et al, 2014). The body responds to trauma with a state of tachycardia, an increased use of oxygen, increased respiratory rate, an increase in body temperature as well as an increase in the negative nitrogen balance of, for example catabolism. The flow phase, also called catabolism, can occurs more than 2 days post-trauma. The flow phase is an early period of catabolism that provides a compensatory response to early trauma and volume replacement, except in the case of most minor injuries. In this phase, the metabolic response is directly related to the supply of energy substrates and proteins to protect the repair of tissue damage and the function of critical organs. The increased body oxygen consumption and metabolic rate is among these responses. In the early catabolic stages, catecholamine (adrenaline) is responsible for increased production and energy consumption. High plasma urea is one of the abnormal features of the protein catabolism process accompanied by a negative nitrogen balance.

In the research conducted, not all patients have increased BUN. According to Simsek, et al. (2014) elective surgery and minor surgery may show decreased protein synthesis and protein degradation. Increased levels of nitrogen urine and negative nitrogen balance can be detected early after surgery and the peak is on the 7 th day. Protein catabolism can last for 3-7 weeks. All patients were measured on day 2 so not all patients showed an increase in BUN. After trauma lipolysis increases and fat is used as a source of energy. Lipoprotein lipase is attached to the capillary endothelium which will convert triglycerides into glycerol and free fatty acids. Heparin will release the lipoprotein lipase enzyme into the circulation resulting in intravascular hydrolysis. In trauma lipoprotein lipase muscle activity increases but in adipose tissue decreases in contrast to sepsis this lipase activity in muscle decreases. Surgery affects metabolism and substrate utilization. Post-operation, glucose utilization decreases as insulin time becomes resistant with elevated triglycerides and free fatty acids. Insulin resistance post-operatively is prevented in elective surgery, e.g. the administrations of carbohydrates prior to surgery (Soop, et al., 2007). In this study, the majority of patients were elective surgery patients, but the researchers did not classify between patients who were undergoing elective surgery and who were not.

The value of AUC between MUST to BUN and blood glucose levels was $56.8 \%$ and $46.1 \%$ with $95 \%$ confidence interval. While the AUC value between MUST to albumin and hemoglobin levels was $64.3 \%$ and $64.3 \%$ with $95 \%$ confidence interval. MUST has a moderate value of accuracy to calculate the risk of malnutrition, but MUST has a very weak accuracy value in relation to metabolic conditions.

\section{Differences in the effectiveness of using Nutritional Risk Screening (NRS-2002) and the Malnutrition Universal Screening Tool (MUST) in relation to metabolic conditions in trauma patients}

According to Schieccer, et al. (2008), a higher 2002 NRS score was found to be quite predictive of the risk of complications and death. In Raslan, et al. (2011) which compared the Area Under Curve (AUC) between NRS 2002 and MUST, it shows that NRS 2002 is better than MUST. A study conducted by Ozkhalanli, et al (2009), NRS showed good predictive validity for the occurrence of post-operative complications.

MUST was originally designed to not only determine nutritional status, but also to predict outcomes in adults, as well as the elderly inpatients. In the study conducted by Henderson, et al. (2008) 
MUST with NRS 2002 was used to predict mortality in older patients who were inpatients, in which the studies examined indicated less mortality, so MUST therefore has poor predictive validity. Further study of MUST's predictive validity in the elderly population is needed. In 2006, the Association Dietician Indonesia (AsDI) began introducing the Proses Asuhan Gizi Terstandar (PAGT) adopted from the Nutrition Care Process, created by the American Dietetic Association (NCP-ADA). The PGAT was prepared as an effort to provide quality nutritional care. The process supports and leads to individual nutritional care. The Standard Nutrition Care Process consists of 4 steps ranging from nutritional assessment, nutrition diagnosis, nutritional intervention, monitoring and evaluation. The advantage of this study, is that it can quickly and easily predict the trauma patient's nutritional condition. so the risk of metabolic conditions can be treated early. A limitation of this study was not examining the hormone levels, during the biochemical examination. This is because the metabolic response is strongly influenced by the hormone levels of trauma patients. In hospitals, the NRS-2002 instrument is better suited to predicting the presence of metabolic conditions in trauma patients than MUST.

Nutrition screening is an entry into the PAGT cycle, with the goal being to obtain sufficient information to identify any relationships with nutritional problems. Patients who are identified as malnourished need nutritional care through screening and referral. Nutrition screening should be a simple and quick process that can be done by nurses and medical staff (Barendregt, 2008). The assessment of the nutritional status of hospitalised patients will result in better accuracy when it comes nutritional interventions so as to enhance biochemical and clinical indicators. This has an impact on the outcome of hospitalisation, accelerating the disease and reducing the complication of disease, so that it can shorten the length of hospitalisation and preventing the malnutrition of the hospital patient. Nutrition services in hospitals are the right of everyone, and require a guideline to obtain quality service results. Quality nutrition services in hospitals will assist the patient's healing process, which means shortening the length of their stay, which can save medical expenses.

\section{CONCLUSION}

There is a significant difference in effectiveness between the uses of Nutritional Risk Screening (NRS2002) with the Malnutrition Universal Screening Tool (MUST) in relation to change in the metabolic conditions of trauma patients. The use of the NRS2002 instruments is more effective than the MUST for measuring changes in the metabolic conditions of trauma patients. NRS 2002 has the ability to identify patients not in metabolic negative state, and the value of NRS 2002 accuracy is higher than MUST.

\section{REFERENCES}

Al Kalaldeh, M., \& Shahin, M. (2014). Nurses' knowledge and responsibility toward nutritional assessment for patients in intensive care units. Journal of Health Sciences, 4(2), 90. Retrieved from

http://ezproxy.stir.ac.uk/login?url=http://search .ebscohost.com/login.aspx?direct=true $\& \mathrm{db}=\mathrm{edb} \&$ $\mathrm{AN}=100323167 \&$ site $=$ eds-live

Ansari, M. R., Susetyowati, \& Pramantara, I. (2014). Uji validitas skrining status gizi NRS 2002 dengan asesmen biokimia untuk mendeteksi risiko malnutrition di RSUP dr. Sardjito yogyakarta. Gizi Indon, 37((1)), 1-12.

Barendregt, K., P.B. Soeters, S.P. Allison and J.Kondrup, 2008. Basic concepts in nutrition: Diagnosis of malnutrition: Screening and assessment. e-SPEN, E. Spen. Eur. E. J. Clin. Nutr. Metab., 3: 121-125.

Chen, Z. Y., Gao, C., Ye, T., Zuo, X. Z., Wang, G. H., Xu, X. S., \& Yao, Y. (2015). Association between nutritional risk and routine clinical laboratory measurements and adverse outcomes: A prospective study in hospitalized patients of wuhan tongji hospital. European Journal of Clinical Nutrition, 69(5), 552-557. https://doi.org/10.1038/ejcn.2014.239

Jayawardena, R., Lokunarangoda, N. C., Ranathunga, I., Santharaj, W. S., Walawwatta, A. O., \& Pathirana, A. K. (2016). Predicting clinical outcome of cardiac patients by six malnutrition screening tools. BMC Nutrition, 2(1), 5. https://doi.org/10.1186/s40795-016-0044-z

Kondrup, J., Allison, S. P., Elia, M., Vellas, B., \& Plauth, M. (2003). ESPEN guidelines for nutrition screening 2002. Clinical Nutrition, 22(4), 415$421 . \quad$ https://doi.org/10.1016/S02615614(03)00098-0

Kuppinger, D., Hartl, W. H., Bertok, M., Hoffmann, J. M., Cederbaum, J., Bender, A., ... Rittler, P. (2013). Nutritional screening for risk prediction in patients scheduled for extra-abdominal surgery. Nutrition, 29(2), 399-404. https://doi.org/10.1016/j.nut.2012.06.013

Lee, J. O., Benjamin, D., \& Herndon, D. N. (2005). Nutrition Support Strategies for Severely Burned Patients. Nutricion on Clinical Practice, 20(June), 325-330.

Leuenberger, M., Kurmann, S. \& Stanga, Z. Support Care Cancer (2010) 18(Suppl 2): 17. https://doi.org/10.1007/s00520-009-0805-1

Lomivorotov, V. V., Efremov, S. M., Boboshko, V. A., Nikolaev, D. A., Vedernikov, P. E., Lomivorotov, V. N., \& Karaskov, A. M. (2013). Evaluation of nutritional screening tools for patients scheduled for cardiac surgery. Nutrition, 29(2), 436-442. https://doi.org/10.1016/j.nut.2012.08.006 
MacLeod, J. B. a. (2005). Guidelines for Essential Trauma Care. The Journal of Trauma: Injury, Infection, and Critical Care, 58(3), 652-653. https://doi.org/10.1097/01.TA.0000157822.402 27.F2

Nugrahani, Azizah. (2007). Hubungan Asupan Protein terhadap Kadar Urea Nitrogen, Kreatinin, dan Albumin Darah Pasien Penyakit Gagal Ginjal Kronik yang menjalani hemodialisis di RSUP dr. Sardjito Yogyakarta. Skripsi. Yogyarkarta:Universitas Gadjah Mada, 2007.

Plebani, M. (2012). (2013) Quality Indicators To Detect Pre-Analytical Errors In Laboratory Testing.pdf, 33(August), 85-88.

Raslan, M., Gonzalez, M. C., Torrinhas, R. S. M. M., Ravacci, G. R., Pereira, J. C. R., \& Waitzberg, D. L. (2011). Complementarity of Subjective Global Assessment (SGA) and Nutritional Risk Screening 2002 (NRS 2002) for predicting poor clinical outcomes in hospitalized patients. Clinical Nutrition (Edinburgh, Scotland), 30(1), 49-53. https://doi.org/10.1016/j.clnu.2010.07.002

Schiesser, M., Muller, S., Kirchhoff, P., Breitenstein, S., Schafer, M., \& Clavien, P.-A. (2008). Assessment of a novel screening score for nutritional risk in predicting complications in gastro-intestinal surgery. Clinical Nutrition (Edinburgh, Scotland), 27(4), 565-570. https://doi.org/10.1016/j.clnu.2008.01.010

Sobrino, J., \& Shafi, S. (2013). Timing and causes of death after injuries. Proceedings (Baylor University. Medical Center), 26(2), 120-3.

\section{Retrieved}

from

http://www.pubmedcentral.nih.gov/articlerende r.fcgi?artid=3603725\&tool=pmcentrez\&renderty pe=abstract

Şimşek, T., Şimşek, H. U., \& Cantürk, N. Z. (2014). Response to trauma and metabolic changes: posttraumatic metabolism, 153-159. https://doi.org/10.5152/UCD.2014.2653Jakob, S. M., \& Stanga, Z. (2010). Perioperative metabolic changes in patients undergoing cardiac surgery. Nutrition, 26(4), 349-353. https://doi.org/10.1016/j.nut.2009.07.014

Soop, M., Nygren, J., Thorell, A., \& Ljungqvist, 0. (2007). Stress-induced insulin resistance: recent developments. Current Opinion in Clinical Nutrition and Metabolic Care, 10(2), 181-186. https://doi.org/10.1097/MC0.0b013e32801481 df

Simanjuntak, T. (2010). Hubungan Skrinning Gizi NRS 2002 dan MUST dengan Asesmen biokimia pada Pasien Bangsal Penyakit Dalam dan Syarap RSUP Dr. SardjitoYogyakarta. Skripsi. Yogyakarta:Universitas Gajah Mada, 2010.

Weekes, C. E., Elia, M., \& Emery, P. W. (2004). The development, validation and reliability of a nutrition screening tool based on the recommendations of the British Association for Parenteral and Enteral Nutrition (BAPEN). Clinical Nutrition (Edinburgh, Scotland), 23(5), 1104-1112. https://doi.org/10.1016/j.clnu.2004.02.003 